\title{
Why swimming is just as difficult as dying for Japanese learners of English
}

\author{
Alison Gabriele, Gita Martohardjono \& William McClure \\ Graduate Center, City University of New York \\ agabriele@gc.cuny.edu
}

\begin{abstract}
While both Japanese and English have a grammatic al form denoting the progressive, the two forms (te-iru \& be+ing) interact differently with the inherent semantics of the verb to which they attach (Kindaichi, 1950; McClure, 1995; Shirai, 2000). Japanese change of state verbs are incompatible with a progressive interpretation, allowing only a resultative interpretation of $\mathrm{V}+$ te-iru, while a progressive interpretation is preferred for activity predicates. English be+ing denotes a progressive interpretation regardless of the lexical semantics of the verb. The question that arises is how we can account for the fact that change of state verbs like dying can denote a progressive interpretation in English, but not in Japanese. While researchers such as Kageyama (1996) and Ogihara $(1998,1999)$ propose that the difference lies in the lexical semantics of the verbs themselves, others such as McClure (1995) have argued that the difference lies in the semantics of the grammatical forms, be+ing and te-iru. We present results from an experimental study of Japanese learners' interpretation of the English progressive which provide support for McClure's proposal. Results indicate that independent of verb type, learners had significantly more difficulty with the past progressive. We argue that knowledge of L2 semantics-syntax correspondences proceeds not on the basis of L1 lexical semantic knowledge, but on the basis of grammatical forms.
\end{abstract}

\section{$1 \quad$ Introduction}

In the past decade, research in generative second language (L2) acquisition has focused primarily on issues of syntactic representation, investigating to what extent the principles and parameters of Universal Grammar constrain L2 acquisition. This body of research has closely examined the acquisition of the morphological and syntactic reflexes of L2 functional categories. Specifically, researchers have examined learners' comprehension and usage of L2 inflectional morphology as well as L2 learners' knowledge of feature strength, which is closely tied to constraints on syntactic movement (Epstein, Flynn \& Martohardjono, 1996; Haznedar and Schwartz, 1997; Lardiere, 1998, 2000; Prevost and White, 2000; Schwartz and Sprouse, 1996; Vainikka and Young-Scholten, 1996, among others).

More recently, this focus has broadened to include questions of how knowledge at interface levels is acquired, and how knowledge of peripheral mechanisms interacting with, but outside of UG proper, are deployed to instantiate this knowledge (cf. Juffs, 1996, Juffs and Harrington, 1995; Klein and Martohardjono, 1999). This recent body of research has begun to explore the semantic aspects of L2 acquisition, investigating the interpretations that learners assign to grammatical constructions in a second language (Dekydtspotter, Sprouse and Anderson, 1997; Montrul and Slabakova, 2002; Slabakova and Montrul, 2002). L2 researchers have taken particular interest in the acquisition of lexical semantics and its interaction with argument structure (Juffs, 1996; Hirakawa, 1999, 2001; Inagaki, 1997, 
Montrul, 1997, 1999; Sorace, 1995, 2000) as well as its interaction with grammatical morphology (Montrul and Slabakova, 2002; Slabakova and Montrul, 2002).

Research on the acquisition of aspect falls within this recent L2 research program. Aspect refers to the internal temporal properties of an event (Chung and Timberlake, 1985; Comrie, 1976; Smith, 1991). The aspectual properties of a phrase indicate whether an event is ongoing or whether it is complete. Aspect may be encoded in the lexical class of the verb phrase (lexical aspect) or in particular grammatical forms such as the progressive or simple past morphemes in English (grammatical aspect).

Lexical aspect usually refers to Vendler's (1967) well-established four-way classification of verb phrases. This classification distinguishes statives such as know, which are ongoing in time but generally incompatible with the progressive tense (*John is knowing French), activities such as paint, which are also ongoing in time but unlike states, are usually compatible with the adverbial for an hour-phrase as in John painted for an hour, accomplishments such as run a mile, which unlike activities have a definite terminus and are generally more compatible with the adverbial in an hour phrase as in John ran a mile in an hour, and achievements such as die, which also have a definite terminus but unlike accomplishment verbs, happen instantaneously, with little or no duration.

Aspect can also be encoded in verbal inflectional morphology, for example by perfective and imperfective or progressive and non-progressive grammatical morphemes. The past tense in English encodes perfective aspect as in (1).

\section{(1) John ran a mile.}

Perfective aspect looks at the event as whole, disregarding the internal structure of the event; the verb phrase denotes a completed event. In (1), it is the case that John has run the entire mile. In contrast, English employs the progressive as in (2) to encode imperfective aspect.

\section{(2) John was running a mile.}

Imperfective aspect does not specify either the beginning or endpoint of an event. In (2) the event of John running a mile was in progress at some point in time, but there is no indication of whether the action was actually completed. It is possible that John never in fact ran the entire mile.

It is well known that there is an interaction between lexical aspect and grammatical aspect so that particular grammatical forms yield different interpretations depending on the lexical class of the verb. This particular fact is of central interest to the present study and will be explained further in our discussion of aspectual markers in Japanese. Particular lexical classes of verbs are also incompatible with certain aspectual forms such as stative verbs in English, which are generally considered incompatible with the progressive.

\section{The L2 Acquisition of Aspect}

The interpretation of markers of grammatical aspect is notoriously difficult for second language learners. This observation was pointed out in an early study by Coppietiers (1987) who investigated the ability of near native speakers of French, from varying L1 backgrounds, to distinguish between the French imparfait and passé composé. While the advanced L2 learners were indistinguishable from native speakers on various measures of grammatical knowledge, they deviated from the native speakers to the greatest extent in their knowledge of this aspectual contrast. Although this study has been widely criticized on methodological 
grounds (cf. Birdsong, 1992), it nonetheless drew researchers' attention to the fact that even extremely advanced learners, who have seemingly mastered the L2 syntax, have difficulty with subtle semantic differences between grammatical forms in the second language.

A large body of research has examined the L2 acquisition of aspect from varying theoretical perspectives (Andersen and Shirai, 1996; Bardovi-Harlig, 1992; 1995; Dietrich, Klein and Noyan, 1995; Klein and Perdue, 1992, 1997; Li and Shirai, 2000, Salaberry, 1997, among many others), however it is a relatively new topic within the framework of generative L2 research. Among this growing body of research (Koslowska-MacGregor, 2002; Montrul and Slabakova, 2002; Slabakova, 1997), results from recent studies by Montrul and Slabakova (2002) and Slabakova and Montrul (2002) are particularly relevant to the present study.

Slabakova and Montrul (2002) investigated the acquisition of the perfective-imperfective distinction in Spanish by native speakers of English. Spanish encodes grammatical aspect morphologically: the preterite as in (3a) is used to mark perfective aspect and denotes complete or bounded events. On the other hand, the imperfect as in (3b) is used to mark imperfective aspect and denotes unbounded or incomplete events. English does not have a simplex past form equivalent to the Spanish imperfect. However, with event predicates (activities, accomplishments, achievements), the preterite in Spanish is roughly equivalent to the simple past in English and the imperfect can usually be translated into English with the past progressive. (The interpretation is heavily dependent on context.)

(3a) Julieta practicó tenis.

Julia practice-PRET tennis.

Julia practiced tennis.

(Slabakova and Montrul, 2002) (3b) Julieta practicaba tenis.

Julia practice-IMP tennis.

Julia was practicing tennis.

Stative verbs are incompatible in the progressive in both Spanish and English. However, Spanish morphologically distinguishes the perfective-imperfective contrast with stative verbs as in the examples in (4) whereas English does not, as is shown in the English glosses. The same form, was, is used in both cases.

a. Pedro dijo que María estaba embarazada. (imperfective)

Pedro said that Maria is-IMP pregnant

'Pedro said that Maria was pregnant.' (She was pregnant at that time and she still might be pregnant.)

b. Pedro dijo que María estuvo embarazada. (preterite)

Pedro said that Maria is PRET pregnant

'Pedro said that Maria was pregnant.' (Maria was pregnant and is no longer pregnant.)

(Slabakova and Montrul, 2002 cf. (13))

Slabakova and Montrul predicted that this mismatch in the morphology would cause difficulty for learners of Spanish. L2 learners would have to realize that while English neutralizes the bounded-unbounded distinction with stative verbs, Spanish does not.

Following the theoretical framework of Giorgi and Pianesi (1997), Montrul and Slabakova assume a parametric difference between English and Spanish in the feature composition of the functional category AspP. In English all event predicates (not states) are marked with the feature [+perfective], which encodes boundedness. All event predicates in English must check 
this feature in AspP. In Spanish, on the other hand, verbs are not inherently associated with semantic features. Instead the features [+/-perfective] are associated with overt tense morphology and must also be checked in AspP. Montrul and Slabakova assume that in Spanish, the features (+) and (-) perfective are checked overtly in AspP through imperfective and preterite tense morphology. In this framework, the successful acquisition of aspectual contrasts such as the perfective-imperfective distinction, is evidence of semantic feature assignment under the functional category, AspP.

Slabakova and Montrul found that advanced learners were in fact sensitive to the preteriteimperfect contrast across all verb types, including statives. Contrary to their predictions, statives were not more difficult than event predicates. Their results point to the interesting possibility that learners do not directly transfer the aspectual properties of lexical classes from their L1. This is a result that we will return to in our discussion. In general, Slabakova and Montrul conclude that the L2 learners' ability to distinguish the semantic differences of the aspectual markers in the L2 provides evidence that L2 acquisition is constrained by Universal Grammar and that L2 learners can acquire features of functional categories that are not instantiated in their L1.

\subsection{Present Study}

The present study, like those of Slabakova and Montrul, focuses on how knowledge at the interface between syntax and semantics and syntax and the lexicon is acquired. We are interested in the interaction between lexical and grammatical aspect. However, we have framed our research questions from a different perspective. While it is true that aspectual differences across languages can be explained in terms of the semantic features of syntactic functional categories, as in the theoretical framework of Giorgi and Pianesi (1997), we propose these differences can also be viewed from a purely lexical semantic perspective.

Crosslinguistic aspectual differences may be the result of differences in the semantics of the verbs or in the grammatical forms themselves. Our study investigates how Japanese learners acquire the aspectual properties of the English verb+inflectional morphology complex. We want to know whether existing knowledge of the L1 plays a role through transfer and specifically we investigate what in the semantic representation is transferred when learners acquire language specific interpretations for the V+inflectional morphology complex.

\section{The Progressive in Japanese and English}

Our study focuses on a specific difference in the interpretation of the aspectual marker denoting the progressive in Japanese and English. While both languages have a grammatical form denoting the progressive, the two forms, be+ing in English and te-iru in Japanese, interact differently with the lexical semantics of the verb to which they attach. For the purposes of the present study, we will focus on the interaction with activity and change of state verbs. Change of state verbs fall into the class of achievement verbs in Vendler's (1967) classification.

\subsection{Japanese te-iru}

Te-iru is an aspectual marker, composed of the gerund te plus the verb of animate existence, or auxiliary iru. The construction has been widely discussed in the literature on Japanese aspect because it allows contradictory interpretations: progressive and perfective (Kindaichi, 1950; Fujii, 1966; Okuda, 1978; Jacobsen, 1992; McClure, 1993, 1995; Uesaka, 1995; 
Ogihara, 1998, 1999; Shirai, 2000). The particular interpretation that te-iru denotes is heavily dependent on the lexical semantics of the verb to which it attaches.

The preferred interpretation for activity verbs under te-iru is progressive as is shown in the example in (5).

(5) Tarô-ga hasit-te-iru.

Tarô-topic run-te-iru PRES

Tarô is running.

There are other interpretations available for activity verbs under te-iru that we will return to later in our discussion.

Change of state verbs behave differently under te-iru as is shown in the example in (6); the interpretation of a change of state verb under te-iru is always perfective.

(6) Hikôki-ga kûkô-ni tsuite-iru.

plane-nom airport at arrive te-iru PRES

The plane (arrived and) is at the airport.

(Hirakawa, 2001)

The example in (6) crucially does not allow the progressive reading, The plane is arriving at the airport.

\subsection{English be+ing}

Unlike Japanese, both activity and change of state verbs behave similarly under the English progressive form, be+ing (Vendler, 1967; Dowty, 1979; Landman, 1992). In both cases, the verbs denote ongoing, progressive interpretations as can be see in (7) and (8).

\section{(7) Adrian is running.}

(8) The plane is arriving at the airport.

However, unlike activity verbs, change of state verbs in the progressive do not entail the perfective, so The plane is arriving does not entail The plane has arrived while Adrian is running does entail that Adrian has run at least a step or two (cf. Dowty, 1979 and Landman, 1992 on the Imperfective Paradox).

\subsection{What is the locus of difference between Japanese and English?}

When we compare the grammatical forms denoting the progressive in Japanese and English, we see that Japanese te-iru allows both progressive and perfective interpretations depending on the lexical semantics of the verb whereas English be+ing always denotes a progressive interpretation, regardless of the verb stem. The main difference is that change of state verbs under Japanese te-iru must focus on the resulting state of the event. In (6) above, for example, the focus is on the endpoint of the plane's arrival at the airport. In English, on the other hand, the focus in (8) is on the process leading up to the change of state, the events leading up to the plane's actual arrival.

This contrast has been of particular interest to researchers working on aspect in Japanese. The question that arises is how we can account for the fact that change of state verbs, like dying, 
can denote a progressive interpretation in English, but not in Japanese. There are at least two ways of accounting for this contrast: either by placing the difference in the lexical semantics of the verb or in the semantics of the grammatical form itself.

\subsubsection{The difference is in the verb}

Proponents of the first hypothesis have posited a lexical semantic difference between change of state verbs in Japanese and English (Kageyama, 1996; Ogihara, 1998, 1999). According the Ogihara (1999), "achievements in English can describe preparatory stages but not result stages of events, whereas instantaneous sentences in Japanese are exactly the opposite" (Ogihara, 1999, p. 338-339).

Kageyama (1996) proposes that a Japanese change of state verb such as 'sinu' (die) in (9) has the semantic operator BECOME while the English equivalent in (10) has the semantic operator MOVE.

(9) [y BECOME [y BE DEAD]] 'sinu' Japanese

\section{(10) [y MOVE [y TO DEAD]] 'die' English}

Both structures imply a resulting state, however BECOME in (9) is telic (meaning that specifies an inherent endpoint) while MOVE in (10) is atelic, and thus allows a progressive interpretation. Activity verbs, on the other hand, will have the same lexical semantic representation in both languages.

\subsubsection{The difference is in the progressive operator}

Under the second hypothesis, McClure (1995) has argued that change of state verbs are semantically equivalent in Japanese and English. McClure's proposal shifts the focus to the semantics of the grammatical form as the locus of crosslinguistic differences. McClure's (1995) work expands upon traditional analyses of the progressive form in English, such as Landman (1992), which analyze be+ing as a semantic operator PROG which interacts with the verb stem to which it attaches as in (11).

(11) PROG (verb)

In McClure's analysis, the differences in the interpretation between the English and Japanese progressive forms lie in the formal semantic properties of be+ing and te-iru as you can see in (12) and (13).

(12) Be+ing

$\operatorname{PROG}(\mathrm{P})=1$ during the interval $\mathrm{i}$ iff

$$
\begin{aligned}
& \text { [1] } \exists a ̊ \text { s.t. } \stackrel{\circ}{0} \mathrm{P} \& \tau(\stackrel{\circ}{a})<\mathrm{i} \&
\end{aligned}
$$

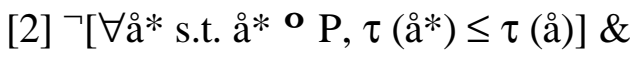

$$
\begin{aligned}
& \text { [3] } \forall \mathrm{a}^{\prime}\left[\left[\forall \stackrel{\circ}{*}^{*} \text { s.t. } \mathrm{a}^{*} \underline{\mathrm{o}} \mathrm{P}, \tau\left(\mathrm{a}^{*}\right) \leq \tau\left(\mathrm{å}^{\prime}\right)\right] \rightarrow \tau\left(\mathrm{a}^{\prime}\right)>\right.\text { i] }
\end{aligned}
$$

$B e+i n g$ is true during the interval $\mathrm{i}$ if [1] there is a segment å of a predicate $\mathrm{P}$ which is manifested before $i$, the interval of evaluation; [2] it is not the case that this segment is later than all other segments of the predicate (i.e. å is not a final segment) and [3] any segment which is a final segment is manifested after the interval of evaluation. The progressive is true 
for a particular interval of time if during that interval the eventuality has begun but is not yet complete.

\section{(13) Te-iru}

$\operatorname{PROG}(\mathrm{P})=1$ during the interval i iff

$$
\begin{aligned}
& \text { [1] } \exists a ̊ \text { s.t. å } \cong \mathrm{P} \& \tau(\stackrel{\circ}{\mathrm{a}})<\mathrm{i} \&
\end{aligned}
$$

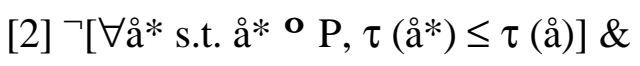

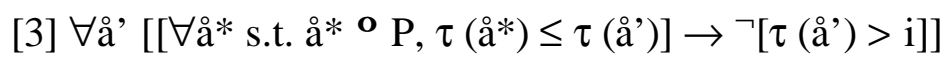

The te-iru construction is true during the interval $\mathrm{i}$ if [1] there is a segment å of a predicate $\mathrm{P}$ which is manifested before $i$, the interval of evaluation; [2] it is not the case that this segment is later than all other segments of the predicate (i.e. å is not a final segment) and [3] all segments which are final are also manifested at the time of evaluation or in the past. The progressive is true for a particular interval of time if during that interval the eventuality has begun and if possible, is also complete. All possible final segments must be realized during that interval.

The basic difference in (12) and (13) can be summed up as follows: The semantics of be+ing require that no final segment of an eventuality is realized whereas the semantics of te-iru require that all final segments of an eventuality are realized (McClure, 1995).

\subsection{L2 Predictions for the Progressive}

If we assume that there will be transfer of L1 semantics, then we can outline different predictions for the L2 acquisition of change of state verbs under the English progressive be+ing based on the two semantic models presented above. Under the first hypothesis, where crosslinguistic differences lie in the verbs themselves, the goal of the L2 learner is to assign the correct lexical semantics of the corresponding verb in English. Change of state verbs might present difficulty for the Japanese learner or English because the lexical semantic representations differ in the two languages. Activity verbs, on the other hand, have equivalent lexical semantic representations in both languages and therefore, should not present any difficulty. We will refer to this hypothesis as the "Transfer of Lexical Semantics" hypothesis. In summary, this model predicts that Japanese learners will perform better on activity verbs than on change of state verbs.

Under the second hypothesis, the verbs themselves are equivalent in Japanese and English. The goal of the L2 learner in this case is to assign the formal semantic properties on the English progressive operator. This model, which we will refer to as the "Transfer of Grammatical Form" hypothesis, predicts equivalent performance across activity and change of state verbs. It further predicts that learners will have difficulty with the English progressive in general because the L1 formal semantic properties are different.

\section{Experimental Study}

\subsection{Target Structures}

In our experimental study we tested the past progressive as our target structure. This choice was essentially required by our design. Ideally we would have targeted the present 
progressive and contrasted learners' performance on the simple present. However, the simple present in English denotes a wide array of interpretations, such as the habitual or narrative interpretation, which made it an unsatisfactory option for our contrast structures; the various interpretations of the English simple present tense are very difficult for L2 learners. Therefore we decided to target progressive aspect in the past tense and contrast learners' performance on the simple past.

The simple past forms, $-e d$ in English and $-t a$ in Japanese, denote basically equivalent perfective interpretations regardless of the lexical semantics of the verb stem to which they attach, as the examples in (14) and (15) demonstrate.

(14) Adrian studied English.
Akiko-wa eigo-o
benkyo-shita.
Akiko-NOM English-ACC
study-PAST
Akiko studied English.

\subsection{Research Questions}

We investigated whether L2 learners can assign target like interpretations to inflectional morphology such as be+ing in English. We were especially interested in whether existing knowledge of the semantics of the first language, Japanese, would play a role through transfer. Specifically, we wished to investigate what transfers in the aspectual domain: the lexical semantic properties of the verbs or the semantic properties of the grammatical forms.

\subsection{Participants}

We tested 83 native speakers of Japanese who were studying English as a foreign language. Based on responses given on a language background questionnaire that we administered, participants were placed in either the Intermediate $(n=38)$ or the Advanced $(n=45)$ group. Participants in the intermediate group were mainly adults who were studying English at conversation schools in rural areas of Japan. All participants in this group had studied English for the mandatory six years in junior and senior high school, but they had not continued their study of English at the university level. The mean age of the intermediate group is 41 .

Participants in the advanced group were mainly junior and senior high school English teachers in rural areas of Japan. All Advanced participants had studied English for the mandatory six years in junior and senior high school and they had continued to study English at the university level for 2-4 years. The mean age of the advanced group is 44 . For participants in both groups, contact with native speakers of English is limited to contact with foreign teachers (mostly from the U.S. and England) who are employed by the conversation schools and the public junior and senior high schools.

We also tested 20 native speakers of English, who were undergraduate students at a large public university in New York City.

\subsection{Design: Interpretation Task}

Learners were tested on their interpretation of activity and change of state verbs in both past progressive and simple past contexts. They were tested on ten verbs: four activity verbs (swim, dance, wash, sing) and six change of state verbs (fall, die, arrive, buy, borrow, lend). 
Learners were asked to judge pairs of sentences such as the ones in (16) and (17) and were instructed to decide whether or not the second sentence presented a possible continuation of the first sentence. The task was designed to evaluate how learners interpreted the simple past and the past progressive forms.

(16) My niece sang 2 Christmas songs at church. She left church after the first song. $\mathbf{X}$

(17) My niece was singing 2 Christmas songs at church. She left church after the first song.

Given the first sentence in (16) My niece sang 2 Christmas songs at chuch, participants had to decide whether it was possible that She left church after the first song. We expected that native speakers would say that the sentence pair in (16) is not possible. In this case, the simple past tense encodes perfective aspect and therefore the event of the niece singing 2 songs must have been completed in entirety.

However, given the first sentence in the pair in (17), My niece was singing 2 Christmas songs at church, we expected that native speakers would say it is possible that She left church after the first song. In this example, the progressive aspect does not entail completion of the event. It is possible that the niece did not finish singing the two songs that she intended to sing, and in fact, left the church after singing only one.

There were thirty test items in total. Each of the ten verbs appeared in three contexts: in a simple past context, in a past progressive context and in a filler sentence. There were nine sentence types in total; examples are given in (18)- (26). Sentence types were balanced across four test batteries. The judgements we expected from native speakers of English are given in parentheses following each sentence pair.

Our discussion, from this point forward, will focus only on the four target sentence types, given in (18)- (21). The sentence types in (22)-(26) were included to insure that the participants understood the task and to balance the number of items that were expected to be accepted and rejected.

\section{Examples of sentence types}

\section{(18) Activity Verb/ Past Progressive/ Contradictory (accept)}

The Olympic athlete was swimming the whole race. She stopped half way through.

(19) Change of state Verb/ Past Progressive/ Contradictory (accept)

The plane was arriving in Hartford at 3:00. The plane exploded in midair.

(20) Activity Verb/ Simple Past/ Contradictory (reject)

The Olympic athlete swam the whole race. She won the race very easily.

(21) Change of state Verb/ Simple Past/ Contradictory (reject)

The plane arrived in Hartford at 3:00. The plane exploded in midair.

(22) Activity Verb/ Past Progressive/ Neutral (accept)

The Olympic athlete was swimming the whole race. She won the race very easily.

(23) Change of state Verb / Past Progressive/ Neutral (accept)

The plane was arriving in Hartford at 3:00. That day the plane had many passengers.

(24) Activity Verb/ Simple Past/ Neutral (accept)

The Olympic athlete swam the whole race. She won the race very easily. 
(25) Change of state Verb / Simple Past/ Neutral (accept)

The plane arrived in Hartford at 3:00. That day the plane had many passengers.

(26) Filler (reject)

Henry is lending a CD to his friend. Henry has no friends.

\subsection{Predictions: Target Test Sentences}

Our first target sentence type in (18) includes an activity verb in a past progressive context.

We expected that native speakers would accept this pair of sentences. Next we will outline the predictions for the Japanese learners based on the two models we presented earlier.

Given that the lexical semantic representation of activity verbs is equivalent in Japanese and English, the Lexical Semantic Transfer hypothesis predicts that Japanese learners will also accept this pair of sentences.

However, if the Transfer of Grammatical Form model is correct, then learners will have difficulty with the progressive form, regardless of the lexical semantics of the verb. This hypothesis then predicts that learners will incorrectly reject this pair.

The second target sentence type in (19) includes a change of state verb in a past progressive context. We expected that native speakers would accept this pair of sentences. However, in this case, both semantic models predict that Japanese learners will incorrectly reject this pair. According to the predictions of the Lexical Semantic Transfer, learners may transfer the L1 lexical semantic representation for change of state verbs. Therefore they will interpret the first sentence in (19) as The plane arrived in Hartford at 3:00. The plane exploding in midair is then not possible.

The Transfer of Grammatical Form hypothesis also predicts difficulty with the pair in (19) simply because the verb is in the past progressive form.

In order to contrast learners' performance on the past progressive, we also included activity and change of state verbs in the simple past. We expected that native speakers would reject the sentence pairs in (20) and (21). Because the L1 interpretation is basically equivalent, both models predict that Japanese learners will not have difficulty rejecting them as well.

To sum up, we will briefly revisit the predictions of the two models for the past progressive and simple past In the past progressive, the Lexical Semantic Transfer Model predicts facilitation with activity verbs but difficulty with change of state verbs. The Transfer of Grammatical Form model predicts equivalent performance on both classes of verbs.

In the simple past, both models predict equivalent performance across verb types. However, the Transfer of Grammatical Form model predicts that learners will have more difficulty with the past progressive than with the simple past. This is due to the fact that the semantics of the past forms are generally equivalent in the L1 and L2 while the semantics of the progressive form is different.

\section{$5 \quad$ Results}

Only learners and native speakers who were accurate on at least 70\% (7 out of 10) of the filler sentences were retained for the analyses of performance on the four target sentence types outlined above. Overall results are reported in terms of mean percent correct. Standard deviations are given in parentheses. 


\subsection{Comparing Activity and Change of State Verbs}

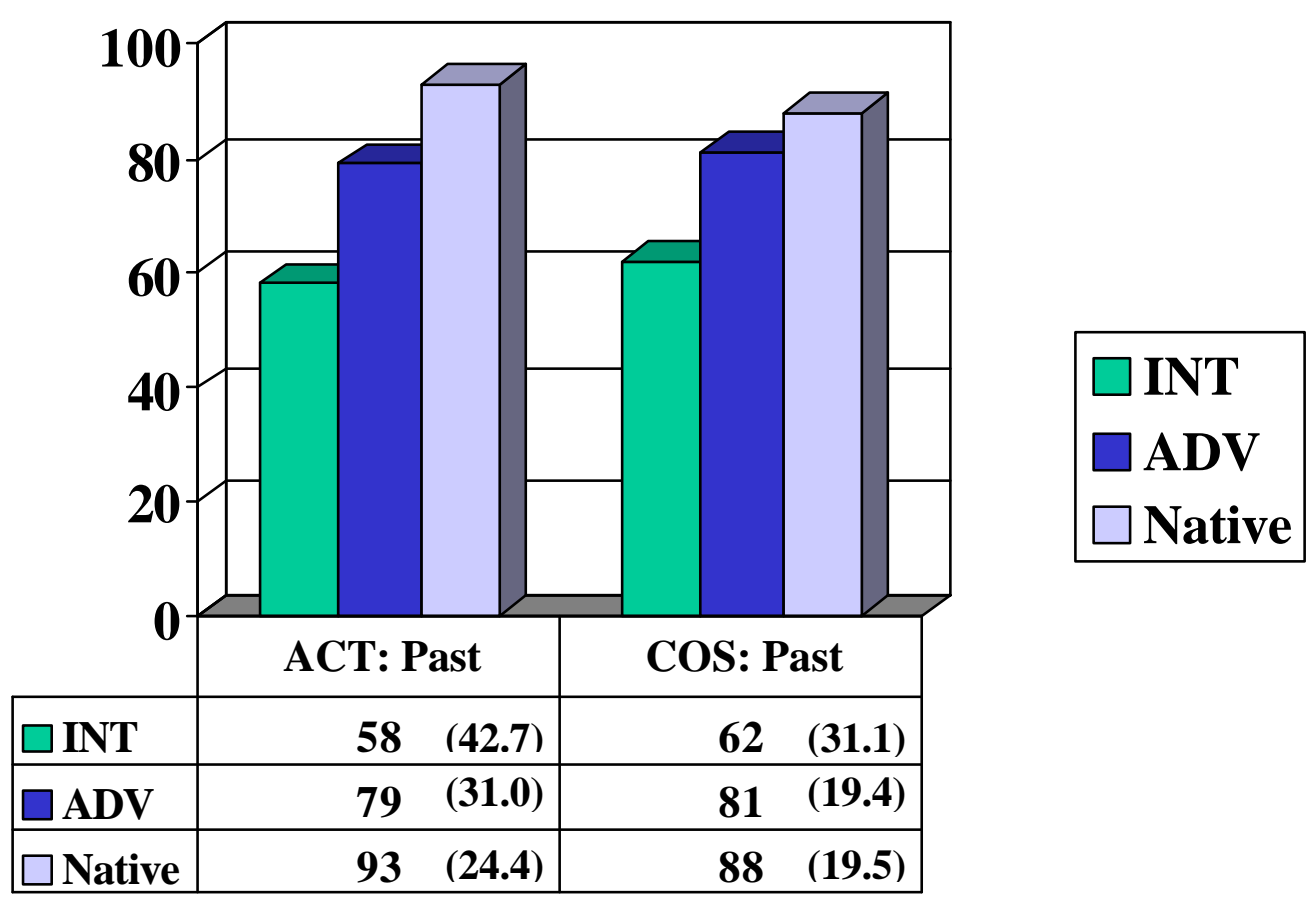

Figure 1. Mean percent correct on activity and change of state verbs in the simple past

Figure 1 summarizes the results of performance on activity and change of state verbs in the simple past. A repeated measures analysis of variance revealed that performance on activity verbs was not significantly different from performance on change of state verbs in the simple past, $\mathrm{F}(1,102)=.023, \mathrm{p}=.879$. Learners treated change of state verbs the same way they treated the activity verbs.

Furthermore, a single-factor analysis of variance indicated that learners in the advanced group did not perform significantly differently from the group of native speakers with either activity verbs $(\mathrm{p}=.318)$ or change of state verbs $(\mathrm{p}=.483)$ in the simple past. Advanced learners performed quite well on the simple past.

Figure 2 summarizes the results of performance on activity and change of state verbs in the past progressive. 


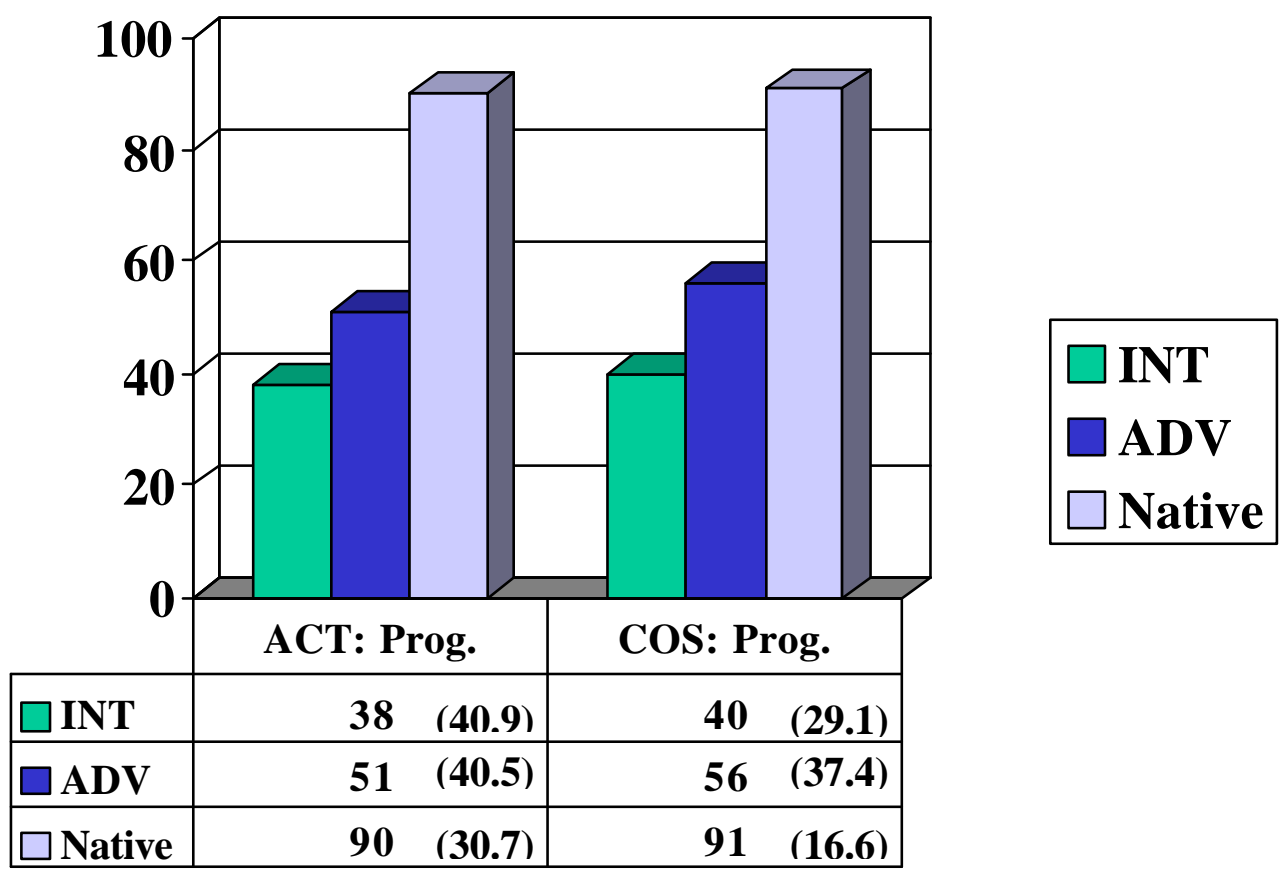

Figure 2. Mean percent correct on activity and change of state verbs in the past progressive

The results in Figure 2 show the same pattern of results as Figure 1. A repeated measures ANOVA revealed that learners again treated activity verbs the same way they treated the change of state verbs. The difference in performance on the two verb classes was not statistically significant, $\mathrm{F}(1,102)=.261, \mathrm{p}=.611$.

However, while the pattern of results is similar, learners' accuracy rates were much lower in the past progressive. A single-factor ANOVA revealed that advanced learners performed significantly differently from the native speakers on both activity $(\mathrm{p}=.001)$ and change of state verbs $(\mathrm{p}=.000)$ in the past progressive.

\subsection{Comparing the Past Progressive and Simple Past}

The results presented in Figures 1 and 2 strongly suggest that the past progressive was significantly more difficult that the simple past for the Japanese learners. However, we wanted to run further statistical analyses, looking at each verb class individually, to compare learners' performance on the past progressive and simple past.

Figure 3 summarizes the results of performance on change of state verbs in the two tenses. A repeated measures analysis of variance revealed that performance on change of state verbs in the simple past was significantly better that performance on change of state verbs in the past progressive, $F(1,102)=14.813, p=.000$. Learners had significantly more difficulty with change of state verbs in the past progressive. 


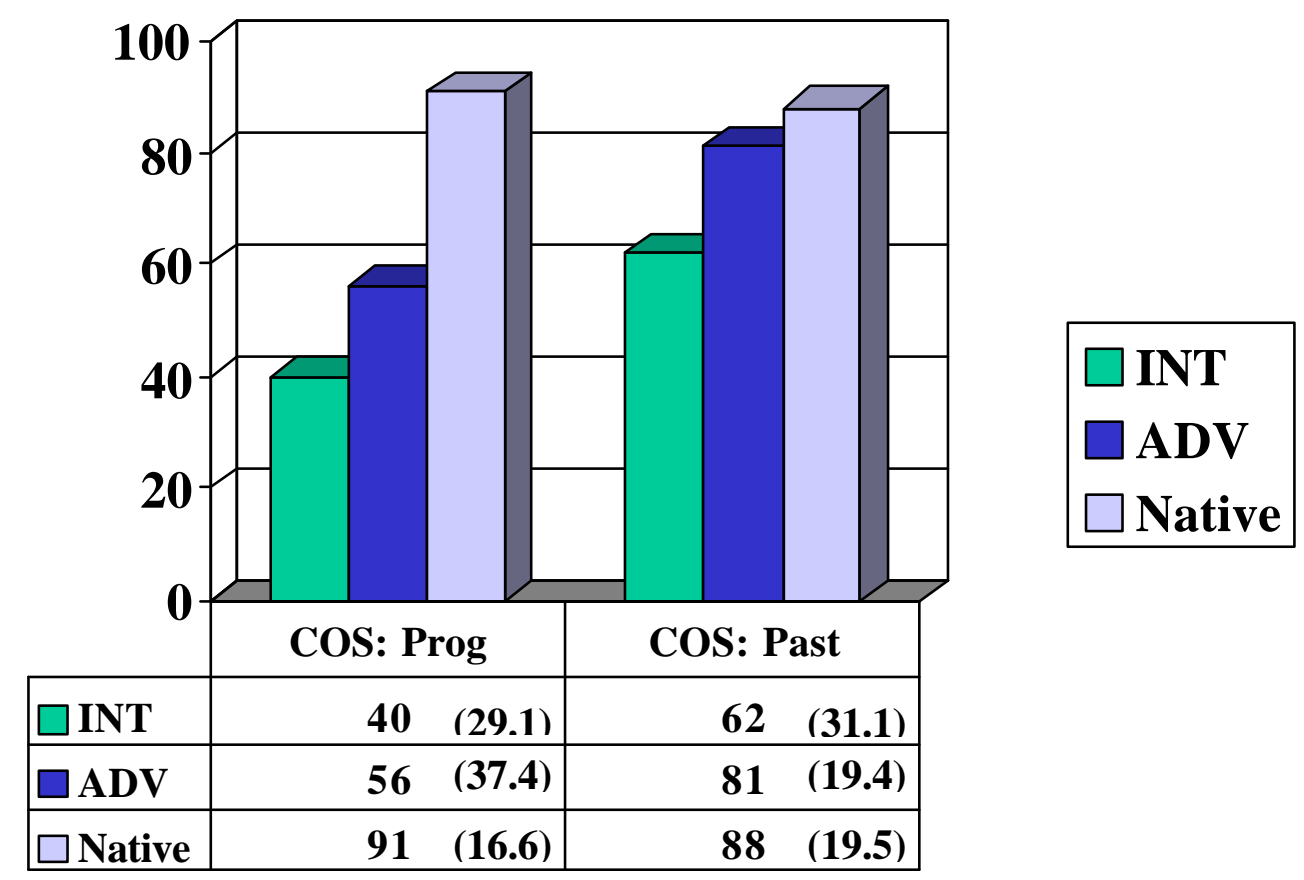

Figure 3. Mean percent correct on change of state verbs in the past progressive and past

The results presented in Figure 4 indicate that the same is true of activity verbs as well. A repeated measures ANOVA revealed that learners' performance on the simple past was significantly better than their performance on the past progressive, $F(1,102)=9.658, p=.002$. In summary, for both activity and change of state verbs, the past progressive was more difficult than the simple past.

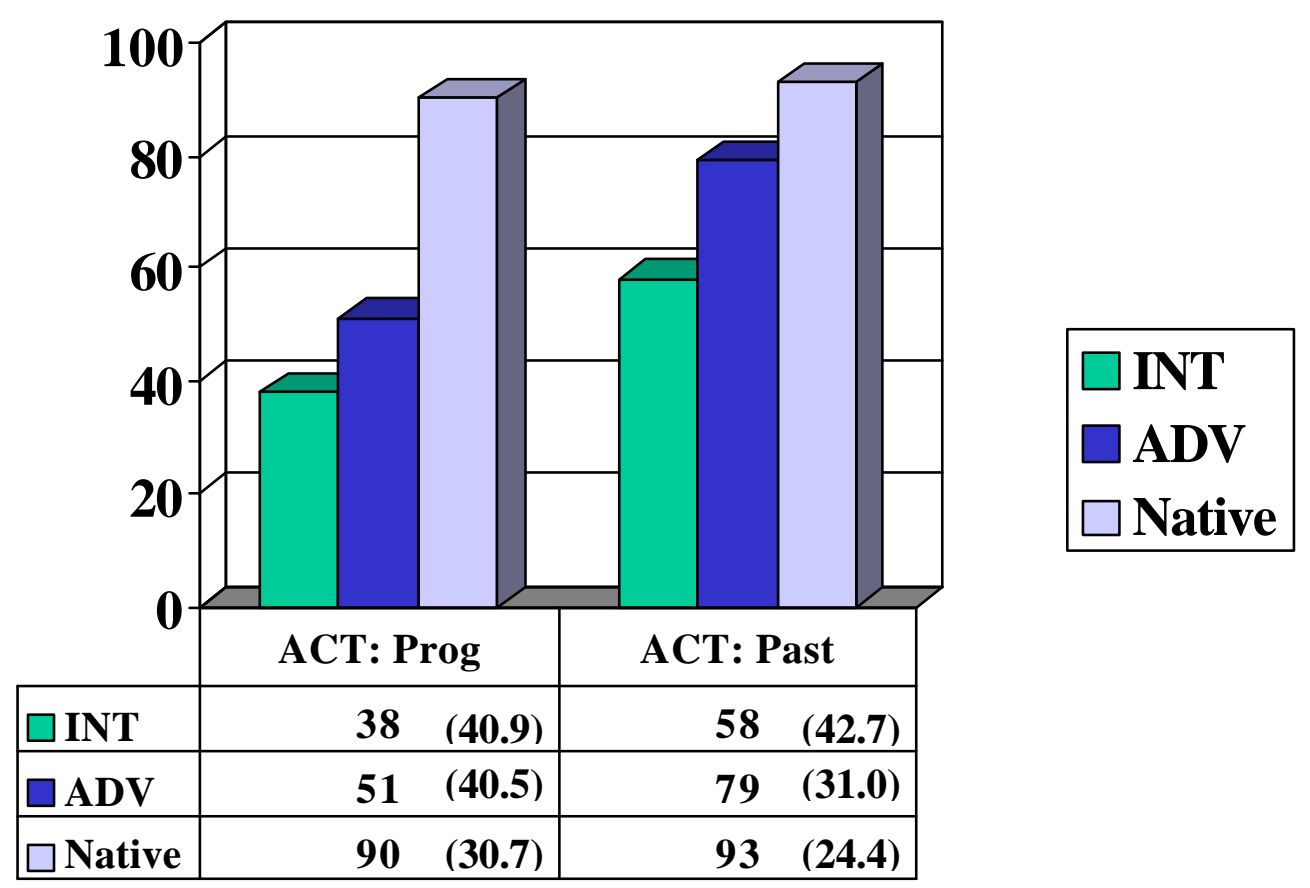

Figure 4. Mean percent correct on activity verbs in the past progressive and past

The above results suggest that contrary to the Lexical Semantic Transfer Model, the difficulty seems to lie not in the particular verb class, but in the progressive form itself. As we would 
expect, performance on the simple past overall was significantly better than performance on the past progressive overall, $\mathrm{F}(1,102)=17.644, \mathrm{p}=.000$. Preliminary results lend support to the second hypothesis; transfer seems to proceed on the basis of grammatical forms.

\subsection{Further Analyses: Investigating Argument Structure}

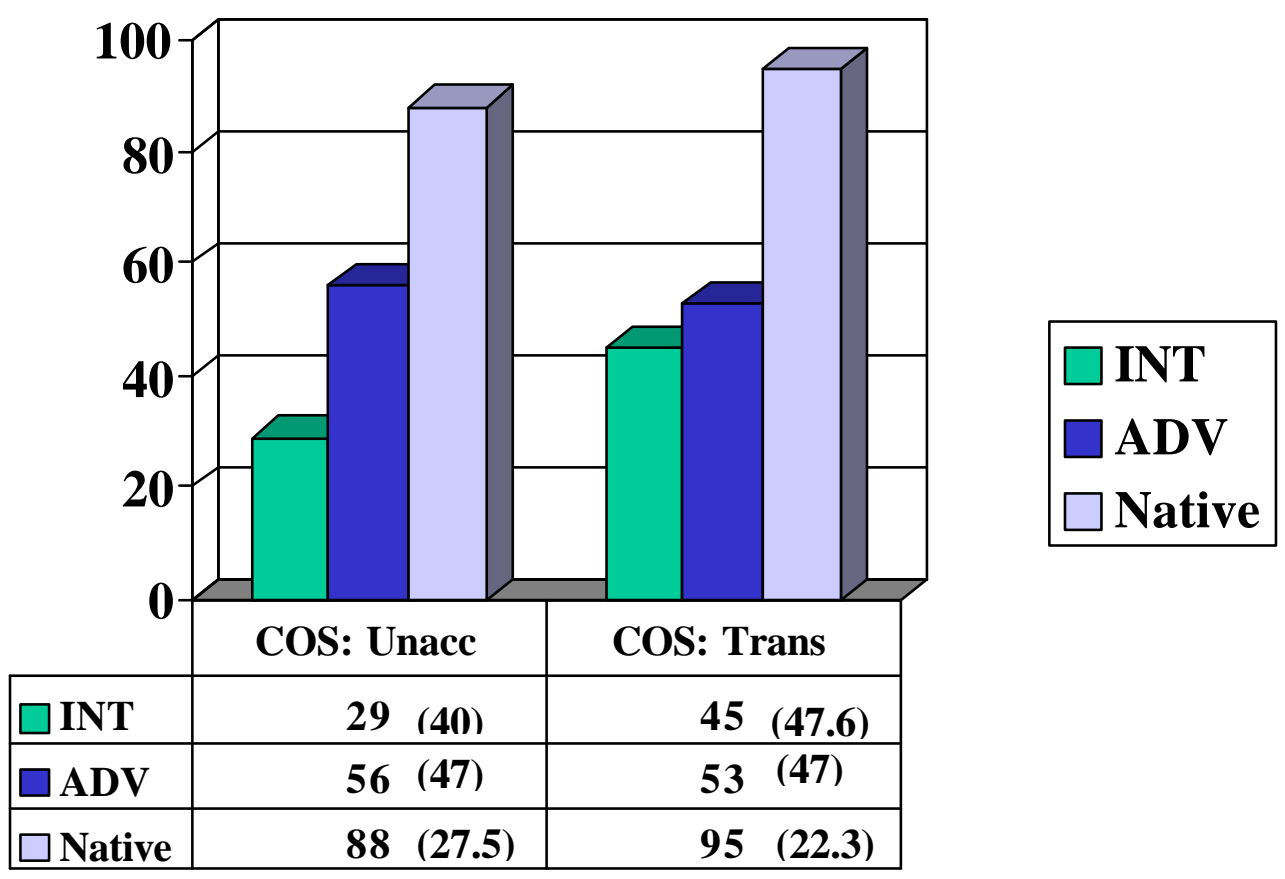

Figure 5. Mean percent correct on unaccusative change of state verbs and transitive change of state verbs in the past progressive

Although our preliminary results provided support for the Transfer of Grammatical Form model, we conducted further analyses that could potentially show support for the first hypothesis, Transfer of Lexical Semantics. Within the class of change of state verbs, we tested three unaccusative verbs (fall, die, arrive) and three transitive verbs (buy, borrow, lend). Unaccusative verbs are intransitive verbs whose single argument is argued to have originated as an underlying object.

In the literature on Japanese aspect, researchers such as Okuda (1977) and Jacobsen (1992) have argued that there is a correlation between transitivity and the meaning that verbs take on under Japanese te-iru. In the example in (27) the interpretation of the unaccusative verb 'sinu' (die) under te-iru is strongly perfective and actually prohibits a progressive interpretation.

(27) Akiko-ga shinde-iru

Akiko-TOPIC die te-iru PRES

Akiko has died.

However, the transitive verb in (28) is not as strongly perfective. While the preferred interpretation is perfective, a progressive or habitual interpretation may also be available, depending on the context. 
(28) Akiko-ga hon-o katte-iru

Akiko-TOP book-ACC buy te-iru PRES

Akiko bought a book.

Given the above differences between intransitive and transitive verbs, if there is an effect of transfer of the L1 lexical representation, then we would expect to see a difference between the two classes of change of state verbs that we tested.

However, the results in Figure 5 suggest that there was not a significant difference between unaccusative verbs and transitive verbs in the past progressive. A repeated measures ANOVA revealed that performance on transitive change of state verbs was not significantly better than performance on unaccusative change of state verbs $(\mathrm{p}=.236)$. These results further suggest that learners are not in fact transferring lexical properties from the L1.

\section{Discussion and Conclusion}

Our results indicates that independent of verb class and argument structure, the past progressive was significantly more difficult than the simple past. We believe that our main finding lends support to Transfer of the Grammatical Form hypothesis. It seems that transfer does not proceed on the basis of L1 lexical semantics, but rather on the basis of grammatical forms. When there is a match between form and meaning in the L1 and L2, as in the simple past, acquisition proceeds with relative ease. However, when there is a mismatch between form and meaning in the L1 and L2, as in the past progressive, even advanced learners have difficulty.

When our learners were given the sentence My niece was singing two Christmas songs at church, they rejected the possibility that She left church after the first song. Learners had difficulty assigning the correct interpretation to the progressive inflectional morphology. Their error strongly suggests that the learners actually interpreted the first sentence as perfective: My niece sang two songs at church. We propose that this error can be explained by transfer of the semantics of the L1 grammatical form.

First let us revisit the interpretation of the Japanese form te-iru. The sentence in (29) repeats example (5).

\section{(29) Tarô-ga hasit-te-iru.}

Tarô-topic run-te-iru PRES

Tarô is running.

As we mentioned earlier, the preferred interpretation for activity verbs plus te-iru as in (5) is progressive. However, in (30) we see that with an implied direct object such as the marathon, a perfective interpretation is also available.

(30) Tarô-ga hasit-te-iru.

Tarô-topic run-te-iru PRES

Tarô ran/ has run (the marathon).

Taro-ga hasit-te-iru is ambiguous between a progressive reading as in (29) and a perfective or result state reading as in (30). The interpretation is dependent on context. Furthermore, an additional perfective reading such as the one in (31) is also available. 
(31) Tarô-ga marason-o hasit-te-iru.

Tarô-topic marathon-ACC run-te-iru PRES

Tarô has had the experience of running a marathon.

(31) is an example of what is called the experiential reading. The sentence can best be interpreted as Taro has had the experience of running a marathon. The examples in (30) and (31) show that while a progressive reading is preferred for activity verbs under te-iru, perfective readings are also available. Change of state verbs under te-iru generally only have a perfective reading available.

Given the availability of the perfective interpretations in (30) and (31), we propose that the Japanese learners overgeneralized the perfective interpretation of the L1 form te-iru onto its nearest equivalent in the L2, English be+ing. Therefore Japanese learners allow a perfective reading for the English progressive regardless of the lexical semantics of the verb and even in cases where the dominant L1 interpretation is progressive, as is the case with activity verbs. For example, they interpret was arriving as arrived but also was running as ran. Our proposal predicts that learners performance on the present progressive will not be significantly different from their performance on the past progressive. If our proposal is correct, the learners would transfer the perfective te-iru to English be+ing in both cases. This makes the very strong prediction that learners will interpret "is running" as ran. Future research on the present progressive is required.

Our proposal has implications beyond the realm of L2 acquisition. First we must investigate why the perfective interpretation of te-iru would transfer across all verb classes. If the above proposal is correct, it would suggest that the perfective is actually a default interpretation in the mental representation of te-iru for Japanese speakers. As we mentioned, future research including a test of the present progressive will shed light on this issue.

While we have argued up until this point that the Transfer of Grammatical Form hypothesis is supported by our findings, it is also possible that there is a developmental explanation for our results. Based on data from studies of child L1 acquisition, Wagner (2002) and Valian (submitted) have independently concluded that children assume that the past is inherently perfective. In Wagner's study, children watch a cat walk down a road and perform activities at different spots on the road. In half of the test sentences, the cat starts to do something at the first X but doesn't complete the activity and then moves to the second X, where the cat begins the activity again. In the other half of the test sentences, the cat completely finishes an action at the first $X$ and them moves on the second $X$ where the cat begins the activity again. In the middle of the cat performing the activity at the second $\mathrm{X}$, the child is asked Where is Kitty $X$ ing? or Where was Kitty X-ing?

Children performed better on the test sentences in the past progressive (Where was Kitty Xing?) in the second half of the test sentences where the first or past event referred to a completed action. Wagner suggests that children may be conflating tense and aspect; therefore they interpret any occurrence of a past marker including the auxiliary was as referring to completed action. Valian also reports depressed performance on the past progressive in her study.

The past progressive may be particularly challenging for both L1 and L2 learners because tense and aspect do not cohere, as they do in the present progressive. Unlike the previous proposal, based on transfer, this developmental model suggests that learners would perform better on the present progressive, than the past progressive. We have begun testing the present 
progressive on a second group of L2 learners. Results of the second experiment will help decide between the competing analyses presented above.

In conclusion, we argue that transfer does nt seem to proceed by verb class. While lexical semantics may in fact play a role, transfer of the semantics of grammatical forms may override transfer of lexical semantics. We believe our results are compatible with the unexpected findings of Slabakova and Montrul's study, which we discussed earlier. In their study learners were expected to have more difficulty with statives because English does not distinguish the preterite and imperfect morphologically with stative verbs. However, this particular verb class did not cause increased difficulty for their learners. These results provide further evidence that L2 learners do not transfer the lexical properties of particular verb classes. The L2 learners of Spanish were able to identify the semantic differences in the preterite and imperfect forms, and through positive evidence found that both grammatical forms are permissible with stative verbs.

Furthermore, we believe our results can help decide between competing theoretical accounts of aspectual differences between Japanese and English. Differences do not seem to lie in the lexical semantics of the verb, as has been suggested by Kageyama (1996) and Ogihara (1998, 1999), but rather, in the semantics of the progressive operator.

\section{Acknowledgements}

This study was supported in part by a research grant from the Research Institute for the Study of Language in Urban Society (RISLUS) of the City University of New York for which we are grateful. The first author would also like to thank the CUNY Council of Foreign Language Learning for a grant which made travel to the Workshop on the Acquisition of Aspect at ZAS possible. We would like to thank the participants of the workshop for many helpful suggestions as well as the organizers, Dagmar Bittner and Natalia Gagarina.

\section{References}

Andersen, R.W. and Y. Shirai. (1994): Discourse motivations for some cognitive acquisition principles. Studies in Second Language Acquisition, 16, 133-156.

Bardovi-Harlig, K. (1995): The interaction of pedagogy and natural sequences in the acquisition of tense and aspect. In F. Eckman, D. Highland, P.W. Lee, J. Mileham, \& R. Rutkowski Weber (eds.), Second Language Acquisition Theory and Pedagogy. Hillsdale, N.J.: Lawrence Erlbaum.

Chung. S. and A. Timberlake. (1985): Tense, aspect and mood. In T. Schopen (ed.), Language Typology and Syntactic Description, Volume 3. Grammatical Categories and the Lexicon. Cambridge, UK: Cambridge University Press.

Comrie, B. (1985): Aspect. Cambridge, UK: Cambridge University Press.

Coppieters, R. (1987): Competence differences between native and near-native speakers. Language, 63, 544 573.

Dekydtspotter, L., R. Sprouse and B. Anderson. (1997): T he interpretive interface in L2 acquisition: the process-result distinction in English-French interlanguage. Language Acquisition, 6, 297-332.

Dowty, D. R. (1979): Word meaning and Montague grammar. Dordrecht and Boston: D. Reidel Publishing Co.

Epstein, S.. S. Flynn and G. Martohardjono. (1996): Second language acquisition: theoretical and experimental issues in contemporary research. Brain and Behavioral Sciences, 19, 677-758.

Fujii,T. (1966): Dooshi + te iru no imi [The Meaning of V+te iru]. Kokugo Kenkyuushitsu 5, Tokyo University.

Haznedar, B. and B. Schwartz. (1997) Are there optional infinitives in child L2 acquisition? In E. Hughes, M. Hughes and A. Greenhill (eds.), Proceedings of the $21^{\text {st }}$ Annual Boston University Conference on Language Development. Somerville MA: Cascadilla Press.

Hirakawa, M. 1999. L2 Acquisition of Japanese unaccusative verbs by speakers of English and Chinese. In K. Kanno (ed.), The Acquisition of Japanese as a second language. Amsterdam: John Benjamins. 
Hirakawa, M. (2001): L2 Acquisition of Japanese Unaccusative verbs. Studies in Second Language Acquisition, 23, 221-245.

Inagaki, S. (1997): Japanese and Chinese learners' acquisition of the narrow range rules for the dative alternation in English. Language Learning 47, 637-669.

Jacobsen, W. (1992): The Transitive Structure of Events in Japanese. Tokyo: Kurosio.

Juffs, A. (1996): Learnability and the Lexicon: theories and second language acquisition research. Amsterdam: John Benjamins.

Juffs, A. and M. Harrington. (1995): Parsing effects in second language sentence processing: subject and object asymetries in wh-extraction. Studies in Second Language Acquisition, 17, 483-516.

Kindaichi, H. (1950): Kokugo Dooshi no Ichibunrui. Gengo Kenkyuu 15, 48-63.

Klein E., G. Martohardjono and V. Valian. (1999): Learning and Using a First and Second Language. CUNY Collaborative Grant.

Klein, E. and G. Martohardjono. (1999): Investigating second language grammars: some conceptual and methodological issues in generative SLA research. In E. Klein and G. Martohardjono (eds.), The development of second language grammars: a generative perspective, 3-34. Amsterdam: John Benjamins.

Koslowska-Macgregor, M. (2002): The nature of 'incompleteness' of the end state grammar. Paper presented at Generative Approaches to Second Language Acquisition 6. University of Ottawa, Canada.

Landman, F. (1992): The Progressive. Natural Language Semantics 1, 1-32.

Lardiere, D. (1998): Case and tense in the fossilized steady state. Second Language Research 14/1, 1-26.

Lardiere, D. (2000): Mapping features to forms in second language acquisition. In J. Archibald (ed.), Second language acquisition and linguistic theory. Oxford:Blackwell.

Li, P. and Y. Shirai. (2000): The acquisition of lexical and grammatical aspect. Berlin: Mouton de Gruyter.

Montrul, S. (1999): Causative errors with unaccusative verbs in L2 Spanish. Second Language Research 15/2, 191-219.

Montrul, S. ( 2000): Transitivity alternations in L2 acquisition: toward a modular view of transfer. Studies in Second Language Acquisition 22/2, 229-273.

Montrul, S. (2001): Introduction to special issue of Studies in Second Language Acquisition 23, 145-151.

Montrul, S. and R. Slabakova. (2002): Acquiring morphosyntactic and semantic properties of aspectual tenses in L2 Spanish. In A.T. Perez-Lerouz and J. Liceras (eds.), The acquisition of Spanish morphosyntax: the L1-L2 connection, 113-149. Dordrecht: Kluwer.

McClure, W. (1993): A semantic parameter: the progressive in Japanese and English. In S. Choi (ed.) Japanese/Korean Linguistics, Vol. 3. Stanford: CSLI.

McClure, W. (1995): Syntactic projections of the semantics of aspect. Tokyo: Hituzi Syobo.

Okuda, Y. (1977): Asupekto no kenkyuu o megutte- Kindaichi teki dankai [On the study of aspect- the I Kindaichi stage]. Miyagi Kyooiku Daigaku Kokugo Kokubun 8.

Ogihara, T. (1998): The ambiguity of the -te iru form in Japanese. Journal of East Asian Linguistics, 7, 87-120.

Ogihara, T. (1999): Tense and aspect. In N. Tsujimura (ed.) The Handbook of Japanese Linguistics, Blackwell, 321-348.

Prevost, P. and L. White. (2000): Missing surface inflection or impairment in second language acquis ition? Evidence from tense and agreement. Second Language Research, 16, 103-133.

Robison, R. (1995): The aspect hypothesis revisited: a cross-sectional study of tense and aspect marking in interlanguage. Applied Linguistics, 16, 344-370.

Salaberry, R. (1997): The development of past tense aspect among adult academic L2 learners. Ph.D. dissertation, Cornell University.

Schwartz, R. and B. Schwartz. (1996): L2 cognitive states and the full transfer/full access model. Second Language Research, 12, 40-72.

Shirai, Y. (2000): The semantics of the Japanese imperfective -teiru: an integrative approach. Journal of Pragmatics, 32, 327-361.

Slabakova, R. (1997): Zero acquisition: second language acquisition of the parameter of aspect. Ph.D. dissertation, McGill University.

Slabakova, R. and S. Montrul. (2002): Aspectual tenses in Spanish L2 acquisition: a UG perspective. In Y. Shirai and R. Salaberry (eds.), Tense-Aspect Morphology in L2 acquisition. Amsterdam: John Benjamins.

Smith, C. (1997): The Parameter of Aspect. Dordrecht: Kluwer. 
Sorace, A. (1995): Acquiring argument structures in a second language: the unaccusative/unergative distinction. In L. Eubank, L. Selinker and M. Sharwoood-Smith (eds.), The current state of interlanguage, 153-175. Amsterdam: John Benjamins.

Sorace, A. (2000): Gradients in auxiliary selection. Language 76/4, 859-890.

Tenny, C. (1987): Grammaticalizing Aspect and Affectedness. Ph.D. dissertation, MIT.

Tenny, C. (1994): Aspectual roles and the syntax-semantics interface. Dordrecht: Kluwer.

Uesaka, M. (1995): The “te-i(ru)" construction in Japanese: interaction between aspect and syntax. M.A. thesis, McGill University.

Vainikka, A. and M. Young-Scholten. (1996): Gradual development of L2 phrase structure. Second language research, 12, 7-39.

Valian, V. (submitted): Young children's understanding of tense.

Vendler, Z. (1967): Linguistics in Philosophy. Ithaca: Cornell University Press. 